\title{
Older hip fracture patients: three groups with different needs
}

Anette H Ranhoff ${ }^{*}$, Kristin Holvik², Mette I Martinsen², Kirsti Domaas², Ludvig F Solheim²

\begin{abstract}
Background: Norway, and particularly Oslo, has the highest reported incidence of hip fractures in the world. It is increasingly common to care for older hip fracture patients in orthogeriatric units where orthopaedic care is combined with interdisciplinary geriatric care. The characteristics and needs of older hip fracture patients are poorly described. The aim of this paper is to describe the characteristics of these patients in order to better understand their need for care and rehabilitation.
\end{abstract}

Methods: This is an observational study based on a quality register for all patients $65+$ years in an orthogeriatric unit who are operated for a hip fracture. The unit covers 250,000 inhabitants in Oslo. Patient data were collected in the aim of quality control. The quality database includes demographic, medical, and functional data collected from routine assessment by the interdisciplinary team.

Results: From January 2007 to September 2009, 1010 patients, included 241 (24\%) from long-term care institutions, were enrolled in the database. Mean age was 85.1 years (SD 7.1), 76\% were female, and $83 \%$ had experienced an indoor fall. Chronic diseases were registered in $88 \%$, and $38 \%$ of the community-dwelling patients had pre-fracture cognitive impairment defined as IQCODE-SF > 3.6. Complications were observed in 51\% of the patients, of which the most common were a need for blood transfusion, delirium, and urinary tract infections. Post-operative orthopaedic infections were rare (3.1\%). Patients from long-term care were older, (87 vs. 84 years, $p<0.001)$, more had American Society of Anaesthesiologists (ASA) score $>/=3(67 \%$ vs. 48\%, $p<0.001)$ and a higher number of chronic medical conditions (mean 2.2 vs. 1.6, $p<0.001$ ). Among community-dwelling patients, those who had fallen indoors were older, more often female, had ASA score $>/=3$, chronic medical conditions, impairment in prefracture $A D L$ and cognitive function, and more complications during hospital stay.

Conclusions: Older hip fracture patients in this orthogeriatric unit may be divided into three groups; patients who are relatively fit and have experienced outdoors falls (17\%), frail community-dwelling patients who have fallen indoors (59\%), and patients from long-term care institutions (24\%). Different caring pathways are needed for these groups.

\section{Background}

Older patients with hip fractures represent an important and large patient group in the acute hospitals. Norway, and Oslo in particular, has the highest reported incidence of hip fractures in the world [1]. In a Government report concerning acute medical care in Norway [2] hip fracture is listed as the most common cause of admission for acute hospital care among persons 90 years and older.

\footnotetext{
* Correspondence: ahranhoff@yahoo.no

'Department of Medicine, Diakonhjemmet Hospital, PB 23 Vinderen, 0319 Oslo, Norway

Full list of author information is available at the end of the article
}

There are strong arguments for improvement of osteoporosis treatment and fall prevention, both in order to reduce future falls and fracture risk, as well as to improve survival and functional outcome. As these patients are known to be older, have comorbid diseases and to be dependent in activities of daily living (ADL), there is a demand for special care units with interdisciplinary geriatric care integrated with orthopaedic care [3-6]. Scientific evidence for orthogeriatric care is described in guidelines from the British Orthopaedic Association (http://www.boa.ac.uk).

Most studies describing patients with hip fractures have excluded patients admitted from long-term care 
and patients who did not provide informed consent. Within the population of hip fracture patients there may be large heterogeneity in characteristics and needs. Patients from long-term care may have specific characteristics, and among community-dwelling patients, falling outdoors may be a marker of a higher functional level in activities of daily living (ADL). The aim of this paper was to describe the characteristics of older hip fracture patients admitted to an orthogeriatric unit, and to compare patients from long-term care with community-dwelling patients with outdoor and indoor falls, in order to better understand their need for care and rehabilitation.

\section{Methods}

This was an observational study based on routine data that was de-identified and entered into a database in the aim of quality improvement in an orthogeriatric unit for patients 65 years and older with hip fractures. The unit covers a population of approximately 250,000 inhabitants, half of the population of Oslo. It is organised in Department of Surgery, and it has 20 ordinary beds and 4 observation beds for pre- and postoperative care. Orthopaedic surgeons, a geriatrician, specially trained nurses, occupational therapist and physiotherapists are working in the unit. The organisation and principles of care of the unit are described in table 1.

\section{Data collection}

We have used data on patients admitted to the orthogeriatric unit from January 2007 to September 2009. Patients younger than 65 years, those with other diagnoses than proximal femoral fracture (S72.0-S72.2 according to ICD10) and those who stayed in other wards than the actual orthogeriatric unit were excluded. All data were collected during routine care and a registration form was completed during the interdisciplinary ward meetings. Data on these forms that fulfilled the inclusion criteria were de-identified and transferred to a database. Demographic data and data about fracture type, type of surgery and comorbidity were collected from all patients. Data about activities of daily living (ADL) and cognitive function were collected from community-dwelling patients only, as nursing home residents are considered to need help with most ADLs and more than $80 \%$ of them suffer from dementia [7]. Severity of co-morbidity expressed by American Society of Anaesthesiologists (ASA) score [8] was registered by anaesthesiologists. The score ranges from I (healthy) to $\mathrm{V}$ (moribund). Type of fracture, surgical procedure and time of surgery was registered by orthopaedic surgeons, while the geriatrician registered medical co-morbidities and complications during stay in hospital.

The occupational therapist, physiotherapists and nurses collected data about function. Pre-fracture cognitive function was assessed by an interview with a next-of-kin using the short form of the Informant Questionnaire on Cognitive Decline in the Elderly (IQCODE-SF) scoring from 0 to 5 . A score of $>3.6$ indicate cognitive impairment $[9,10]$. The Barthel ADL Index (BI) was used to assess pre-fracture function (interview with patient and next-of-kin), and function at discharge (observation by staff). BI is scored from 0 (totally dependent) to 20. A score of 19 or 20 indicates independency in daily life. Nurses measured body weight and height and calculated body mass index (BMI). Delirium was detected by using the Confusion Assessment Method (CAM) [11]. Mortality, length of stay (LOS) and place of discharge were recorded at discharge.

\section{Statistics}

Data were analysed using SPSS version 14.0. Normally distributed continuous variables are presented as mean and standard deviation (SD), while non-normally distributed variables are presented as median with 25 and 75 percentile (Barthel Index, MMSE, LOS, waiting time for surgery). Stratified analyses were performed to compare community-dwelling patients who had fallen indoors and outdoors, and patients with IQCODE-SF $>3.6$ and the others. Continuous normally distributed variables (age and BMI) were compared using t-test. Continuous nonnormally distributed variables (Barthel Index and MMSE) were compared using the Mann-Whitney U test. Percentages were compared by Chi square test. For the variables BMI, Barthel Index and IQCODE-SF, patients with missing data were excluded from the analyses.

\section{Ethics}

This is an observational study based on routine data and no experimental intervention is performed. All data are de-identified when transferred into the database. The patients are not asked to give informed consent. The Norwegian Social Science Data Services (NSD) has approved the database.

\section{Results}

A total of 1010 patients, 65 years and older, were admitted to the orthogeriatric unit and underwent hip fracture repair from January 2007 to September 2009. Characteristics of the patients are shown in table 2 . Mean age was 85.0 years and the oldest patient was 105 years old. Three of four (76\%) were female and $83 \%$ had fallen indoors. The most common types of fracture were fracture of neck of femur (55\%) and pertrochanteric fracture (39\%). Totally $34 \%$ received a hemiarthroplasty.

Almost one-fourth (24\%) were admitted from longterm care institutions, and, except for two, these patients had fallen indoors. They were older (87.1 vs. 84.3 years, $\mathrm{p}<0.001)$, more had ASA score $>/=3(67 \%$ 


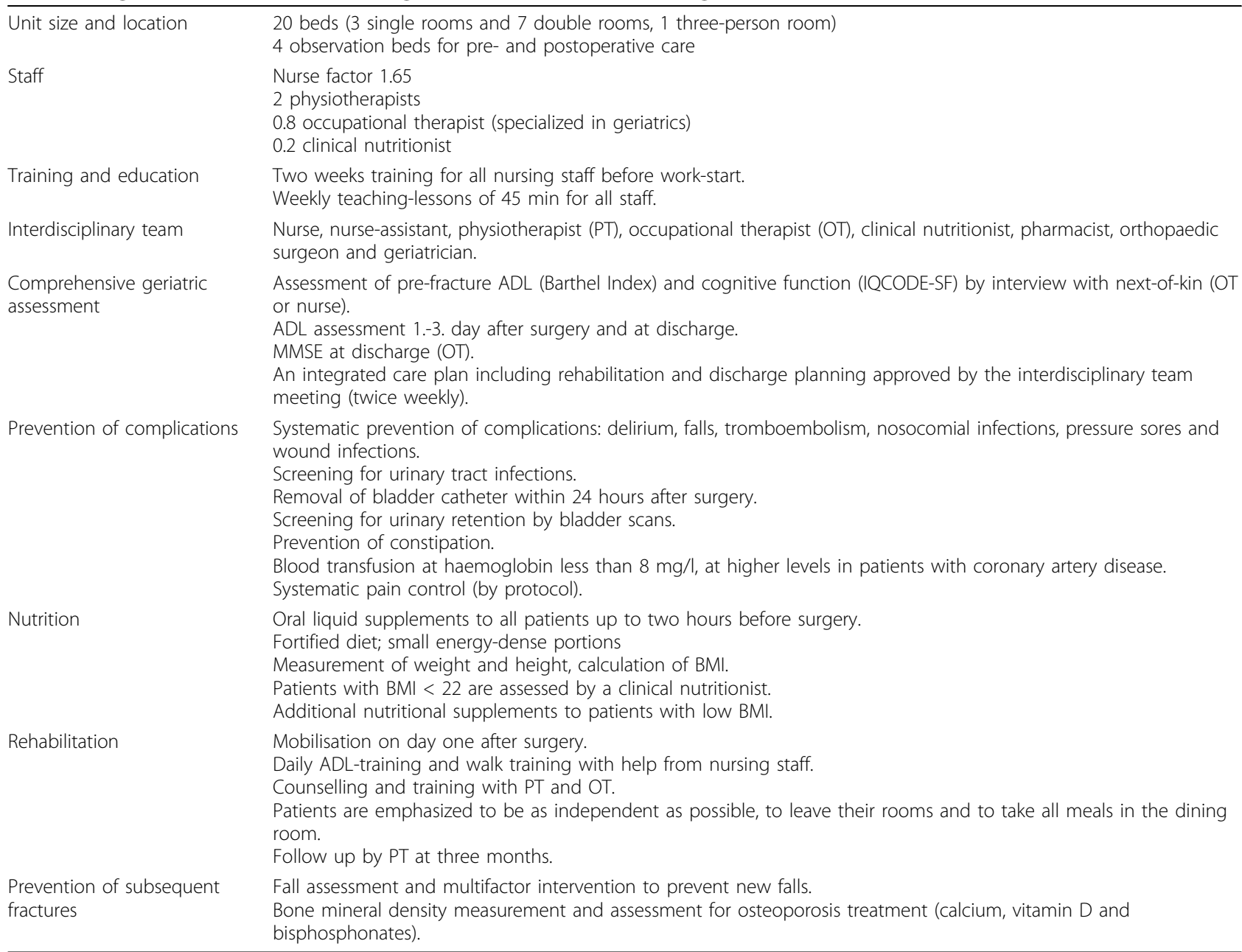

vs. $48 \%, \mathrm{p}<0.001)$ and they had a higher number of chronic medical conditions (mean 2.2 vs. 1.6, $\mathrm{p}<0.001$ ).

Community-dwelling patients with indoor and outdoor falls are compared in table 3. Patients who had fallen indoors were older, more were women, they had poorer general health (ASA score), more chronic medical conditions, impairment in pre-fracture ADL (BI) and cognitive function, and more complications during hospital stay. At discharge, $90 \%$ of patients with indoor falls were dependent in ADL $(\mathrm{BI}<19)$ vs. $60 \%$ of those with outdoor falls $(\mathrm{p}<0.001)$; see figure 1 .

IQCODE-SF score was registered from 511 (66\%) of the community-dwelling patients. There was no difference in age, gender, or ASA score between those registered and those not. Pre-fracture cognitive impairment (IQCODE-SF > 3.6) was found in 192 (38\%) patients. The patients who had cognitive impairment were older (mean 86.1 versus 83.3 years, $\mathrm{p}<0.001)$, more had ASA score $>/=3(55 \%$ versus $43 \%, \mathrm{p}=0.005)$ and more had pre-fracture impairment in ADL (BI < 19) (66\% versus $26 \%, \mathrm{p}<0.001)$. Those with cognitive impairment had also more chronic medical conditions (mean 2.1 versus $1.5, \mathrm{p}<0.001$ ) and complications (mean 1.0 versus $1.5, \mathrm{p}<0.001$ ).

BMI was registered in 521 (68\%) of the communitydwelling patients. Those registered with BMI tended to be younger (mean 84.0 versus 85.0 years, $\mathrm{p}=0.07$ ) and fewer had ASA score $>/=3(46 \%$ versus $53 \%, \mathrm{p}=0.047)$. There was no significant difference in prevalence of low body weight $\left(\mathrm{BMI}<20 \mathrm{~kg} / \mathrm{m}^{2}\right)$ between patients with or without cognitive impairment or between patients who had fallen indoors or outdoors.

\section{Discussion}

The majority of our patients were very old, were women, and had chronic medical conditions. Low body weight, cognitive impairment and impaired pre-fracture ADL were common. At discharge, $84 \%$ of the community-dwelling patients had $\mathrm{BI}<19$, indicating a need for help in daily life and a need for continuation of a rehabilitation program to restore pre-fracture function. 
Table 2 Characteristics of hip fracture patients 65 years and older admitted to an orthogeriatric unit January 2007 - September $2009(n=1010)$

\begin{tabular}{|c|c|}
\hline \multicolumn{2}{|l|}{ Number (\%) if not otherwise stated } \\
\hline Age, years (mean (SD)) & $85.0(7.1)$ \\
\hline Gender, women & $763(75.5)$ \\
\hline Nursing home residents & $234(23.2)$ \\
\hline Indoor fall & $838(83.0)$ \\
\hline \multicolumn{2}{|l|}{$\begin{array}{l}\text { American Society of Anesthesiologists (ASA) score, } \\
n=1009 \text { : }\end{array}$} \\
\hline I - Healthy & $10(1.0)$ \\
\hline II - Mild systemic disease & $468(46.4)$ \\
\hline III - Severe systemic disease & $505(50.0)$ \\
\hline IV - Incapacitating/life-threatening systemic disease & $26(2.6)$ \\
\hline$V$ - Moribund & 0 \\
\hline \multicolumn{2}{|l|}{ Type of fracture } \\
\hline - Fractur neck of femur & $558(55.2)$ \\
\hline - Pertrochanteric fracture & $391(38.7)$ \\
\hline - Subtrochanteric fracture & $61(6.0)$ \\
\hline \multicolumn{2}{|l|}{ Type of surgery } \\
\hline - Screws & $191(18.9)$ \\
\hline - Hemiarthroplasty & $343(34.0)$ \\
\hline - Dynamic Hip Screw & $357(35.3)$ \\
\hline - Intramedullary Hip Screw & $115(11.4)$ \\
\hline - Other (THR or girdlestone) & $4(0.4)$ \\
\hline Body mass index, kg/m2, mean (SD) $(n=550)$ & $22.6(3.8)$ \\
\hline Length of stay, days, median ( 25,75 percentile) & $10(4,16)$ \\
\hline $\begin{array}{l}\text { Waiting time for surgery, hours, median }(25,75 \text { percentile) } \\
(\mathrm{n}=1005)^{*}\end{array}$ & $11(5,19)$ \\
\hline \multicolumn{2}{|l|}{ Place of discharge } \\
\hline $\begin{array}{l}\text { - Short-term stay in nursing home for rehabilitation } \\
\text { and evaluation }\end{array}$ & $336(33.3)$ \\
\hline - Long-term care institution & $234(23.2)$ \\
\hline - Rehabilitation centre & $194(19.2)$ \\
\hline - Home & $176(17.4)$ \\
\hline - Other hospital ward & $45(4.5)$ \\
\hline Died during hospital stay & $25(2.5)$ \\
\hline
\end{tabular}

Based on the results we may divide the patients into three groups with increasingly failing health and function: Community-dwelling elderly who have fallen outdoors (17\%), community-dwelling elderly who have fallen indoors $(59 \%)$ and patients from long-term care institutions (24\%). These findings harmonize well with a study from the UK where different risk profiles for outdoor and indoor falls in older home-dwelling people were found. Indoor falls were associated with frailty and excess mortality, while outdoor falls were associated with compromised health status in more active people [12]. The three groups have different characteristics and needs, but there are some overlapping problems between them. Low body weight is a common trait in all the hip fracture patients, which is equally distributed between patients from the community and is also believed to be common among patients from long-term care institutions [13], although we do not have sufficient BMI data to support this. We found pre-fracture cognitive impairment among $20 \%$ of the patients who had fallen outdoors, and in $38 \%$ of all community-dwelling patients. In the patient records only $21 \%$ were registered with dementia, demonstrating the importance of using systematic assessment with IQCODE-SF to detect cognitive impairment probably due to dementia [10]. Among patients admitted from long-term care facilities, the prevalence of cognitive impairment is probably much higher, as approximately $80 \%$ of patients in Norwegian long-term care institutions have dementia [7].

The strength of this study is that we have data also from patients that are very old, frail and suffering from dementia, and who are often excluded from similar studies. However, unfortunately, the data are not complete for all patients. Missing data are mostly attributed to time-consuming assessments (IQCODE-SF, Barthel Index and $\mathrm{BMI}$ ), which may have a low priority on a busy ward. Although age, gender, and ASA score did not differ between patients who had been assessed with IQCODE-SF and Barthel Index, and those who had not, there may be some bias. We have BMI data for only $68 \%$ of the community-dwelling patients and few of the long-term care patients, indicating an area for quality improvement in the unit. Those registered with BMI tended to be younger and were healthier, probably explaining that they were easier to get on a scale.

Delirium was registered in $22 \%$ of the communitydwelling patients, while other studies have reported more than $50 \%$ during hospital stay [14-17]. In our study, delirium was registered mainly post-operatively and after the patient had moved out from the recovery unit. Nevertheless, delirium is a major problem in older hip fracture patients and systematic prevention has proved to be effective [14-16].

Most of these patients are believed to benefit from orthogeriatric care including optimal medical care, fall prevention assessment, and rehabilitation in order to restore pre-fracture functional status [3-6]. However, the three groups of patients have different needs and may benefit from different care pathways. The communitydwelling patients who have fallen outdoors are the most healthy and youngest. Assessment of osteoporosis and evaluation for treatment with bisphosphonates in addition to calcium and vitamin D supplementation is particularly important in this group [18]. The more frail patients who have fallen indoors may be most in danger for institutionalisation [12] and may benefit from careful discharge planning and continuation of the rehabilitation program after discharge. For patients from longterm care institutions, hip protectors [19] and proper nursing care are probably more important than a 
Table 3 Characteristics of community-dwelling patients

\begin{tabular}{|c|c|c|c|c|}
\hline Characteristic & $\begin{array}{r}\text { All community- } \\
\text { dwelling } \\
(n=769)\end{array}$ & $\begin{array}{r}\begin{array}{r}\text { Community- } \\
\text { dwelling }\end{array} \\
\text { who fell outdoors } \\
(n=170)\end{array}$ & $\begin{array}{r}\begin{array}{r}\text { Community- } \\
\text { dwelling }\end{array} \\
\text { who fell indoors } \\
(\mathrm{n}=599) \\
\end{array}$ & $\mathrm{p}$ \\
\hline Age, years, mean (range) & $84.3(65-100)$ & $82.7(66-100)$ & $84.8(65-100)$ & 0.001 \\
\hline Gender, n (\%) female & $584(75.9)$ & $110(64.7)$ & $474(79.1)$ & $<0.001$ \\
\hline ASA score, $n(\%) \geq 3$ & $368(47.9)$ & $52(30.6)$ & $316(52.8)$ & $<0.001$ \\
\hline BMl, $n(\%)<20 \mathrm{~kg} / \mathrm{m}^{2}(\mathrm{n}=520)^{1}$ & $129(24.8)$ & $24(19.4)$ & 105(26.5) & 0.11 \\
\hline Barthel Index pre-fracture $<19, n(\%)(n=493)^{2}$ & $203(41.2)$ & $23(22.3)$ & $180(46.2)$ & $<0.001$ \\
\hline $\begin{array}{l}\text { Barthel Index at discharge }<19, \mathrm{n}(\%) \\
(\mathrm{n}=316)^{3}\end{array}$ & $265(83.9)$ & $40(59.7)$ & $225(90.4)$ & $<0.001$ \\
\hline IQCODE-SF > 3.6, $n(\%)(n=511)^{4}$ & $192(37.6)$ & $22(20.0)$ & $170(42.4)$ & $<0.001$ \\
\hline \multicolumn{5}{|l|}{ Chronic medical disorders (from patient's records), $n$ (\%) } \\
\hline Dementia & $160(20.8)$ & $16(9.4)$ & $144(24.0)$ & $<0.001$ \\
\hline Pulmonary disease & $107(13.9)$ & $17(10.0)$ & $90(15.0)$ & 0.10 \\
\hline Major vision impairment & $81(10.5)$ & $12(7.1)$ & $69(11.5)$ & 0.09 \\
\hline Major hearing impairment & $73(9.5)$ & $15(8.8)$ & $58(9.7)$ & 0.73 \\
\hline Musculoskeletal disorder & $70(9.1)$ & $20(11.8)$ & $50(8.3)$ & 0.17 \\
\hline Endocrine disorder (other than diabetes) & $67(8.7)$ & $15(8.8)$ & $52(8.7)$ & 0.95 \\
\hline Diabetes mellitus & $60(7.8)$ & $9(5.3)$ & $51(8.5)$ & 0.17 \\
\hline Cerebrovascular disease & $56(7.3)$ & $8(4.7)$ & $48(8.0)$ & 0.14 \\
\hline Psychiatric disorder & $54(7.0)$ & $6(3.5)$ & $48(8.0)$ & 0.043 \\
\hline Osteoporosis with previous fracture & $51(6.6)$ & $7(4.1)$ & $44(7.3)$ & 0.14 \\
\hline Neurologic disorder & $44(5.7)$ & $8(4.7)$ & $36(6.0)$ & 0.52 \\
\hline Cancer & $42(5.5)$ & $9(5.3)$ & $33(5.5)$ & 0.91 \\
\hline Renal failure & $22(2.9)$ & $5(2.9)$ & $17(2.8)$ & 0.94 \\
\hline \multicolumn{5}{|l|}{ Type of medical complication observed during the stay, $\mathbf{n}(\%)$} \\
\hline Need for blood transfusion & $207(26.9)$ & $34(20.0)$ & $173(28.9)$ & 0.021 \\
\hline Delirium (positive CAM) & $169(22.0)$ & $31(18.2)$ & $138(23.0)$ & 0.18 \\
\hline Urinary tract infection & $161(20.9)$ & $19(11.2)$ & $142(23.7)$ & $<0.001$ \\
\hline Pneumonia & $88(11.4)$ & $12(7.1)$ & $76(12.7)$ & 0.042 \\
\hline Fall & $59(7.7)$ & $12(7.1)$ & $47(7.8)$ & 0.73 \\
\hline $\begin{array}{l}\text { Cardiac complications (myocardial infarction, hearth failure, atrial } \\
\text { fibrillation) }\end{array}$ & $49(6.4)$ & $11(6.5)$ & $38(6.3)$ & 0.95 \\
\hline Postoperative wound infection & $26(3.4)$ & $6(3.5)$ & $20(3.3)$ & 0.90 \\
\hline Haematoma & $17(2.2)$ & $2(1.2)$ & $15(2.5)$ & 0.39 \\
\hline Bedsore & $11(1.4)$ & $1(0.6)$ & $10(1.7)$ & 0.47 \\
\hline
\end{tabular}

Outdoor and indoor falls.

${ }^{1}$ BMI was registered in 124 outdoor-fallers and 396 indoor-fallers.

${ }^{2}$ Barthel Index pre-fracture was registered in 103 outdoor-fallers and 390 indoor-fallers.

${ }^{3}$ Barthel Index at discharge was registered in 67 outdoor-fallers and 225 indoor-fallers.

${ }^{4}$ IQCODE-SF was registered in 110 outdoor-fallers and 401 indoor-fallers.

multifactor fall prevention program and intensive rehabilitation.

Rehabilitation of patients with dementia is challenging, but not impossible. Patients with mild and moderate dementia in Finland benefited from systematic rehabilitation after hip fracture, and the majority could be discharged to their own home [20]. In a study comparing intensive muscle strength exercise with ordinary rehabilitation, patients with dementia improved their function most [21].
An alternative way of selecting patients to different care plans could be to use this information and select patients with and without cognitive impairment to different care plans. In total, about $50 \%$ of our hip fracture patients have cognitive impairment, and most of them dementia.

A combination of good orthopaedic care and comprehensive geriatric care seems to be a practical way to care for patients such as those described in this study $[22,23]$. However, the effect and appropriateness of 


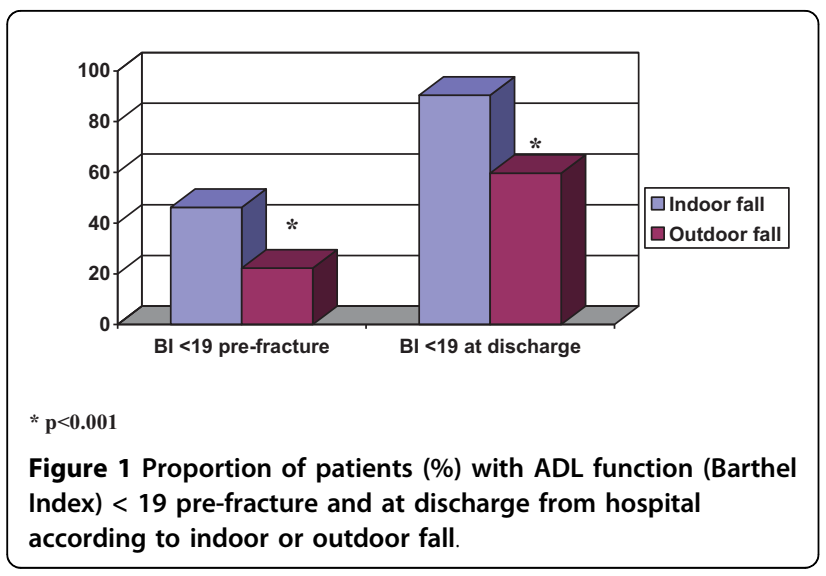

more specific care plans for different groups of patients should be studied further.

\section{Conclusions}

Hip fracture patients in this orthogeriatric unit have high age, are frail with comorbid diseases, and many have cognitive impairment. They may be divided into three groups; patients who are relatively fit and have experienced outdoor falls, frail community-dwelling patients who have fallen indoors, and patients from long-term care institutions. Different caring pathways are needed for these groups.

\section{Acknowledgements}

The authors would like to thank all the patients and the staff at the Orthogeriatric unit in Diakonhjemmet Hospital. The study is entirely sponsored by Diakonhjemmet Hospital.

\section{Author details \\ ${ }^{1}$ Department of Medicine, Diakonhjemmet Hospital, PB 23 Vinderen, 0319 Oslo, Norway. ${ }^{2}$ Department of Surgery, Diakonhjemmet Hospital, Oslo, Norway.}

\section{Authors' contributions}

AHR was responsible for conception and design of the study, acquisition of medical data (comorbidity, complications), analysis and interpretation of data and drafting of the manuscript. KH participated in conception and design, acquisition, analyses and interpretation of data. MIM participated in conception and design, acquisition of administrative and functional data, analyses and interpretation of data. KD participated in conception and design, practical procedures and acquisition of functional data. LFS participated in conception and design, acquisition of surgical data (type of fracture and operation method), analysis and interpretation of data and drafting of the manuscript.

All authors have read and approved the final manuscript.

\section{Authors' information}

$\mathrm{AHR}$ is a geriatrician, $\mathrm{PhD}$ and professor of geriatrics. $\mathrm{KH}$ is a clinical nutritionist and epidemiologist, PhD. MIM is a registered nurse. KD is an occupational therapist. LFS is an orthopedic surgon, $\mathrm{PhD}$ and the chair of the department.

\section{Competing interests}

The authors declare that they have no competing interests.

Received: 18 January 2010 Accepted: 18 September 2010

Published: 18 September 2010

\section{References}

1. Lofthus CM, Osnes EK, Falch JA, Kaastad TS, Kristiansen IS, Nordsletten L, Stensvold I, Meyer HE: Epidemiology of hip fractures in Oslo, Norway. Bone 2001, 29:413-8.

2. Ministry of Health and Care Services: Stortingsmelding nr.43 (1999-2000). Om akuttmedisinsk beredskap. Det Kongelige Sosial- og Helsedepartement 2000.

3. Handoll HH, Cameron ID, Mak JC, Finnegan TP: Multidisciplinary rehabilitation for older people with hip fractures. Cochrane Database Syst Rev 2009, 7(4):CD007125.

4. Lundström $M$, Edlund A, Lundström G, Gustafson Y: Reorganization of nursing and medical care to reduce the incidence of postoperative delirium and improve rehabilitation outcome in elderly patients treated for femoral neck fractures. Scand J Caring Sci 1999, 13:193-200.

5. Stenvall M, Olofsson B, Nyberg L, Lundström M, Gustafson Y: Improved performance in activities of daily living and mobility after a multidisclipinary postoperative rehabilitation in older people with femoral neck fracture: A randomized controlled trial with 1-year follow up. J Rehabil Med 2007, 39:232-238.

6. Vidan M, Serra JA, Moreno C, Ruquelme G, Ortiz J: Efficacy of a comprehensive geriatric intervention in older patients hospitalized for hip fracture: a randomized controlled trial. J Am Geriatr Soc 2005, 53:1476-82.

7. Selbæk G, Kirkevold $\varnothing$, Engedal K: The prevalence of psychiatric symptoms and behavioural disturbances and the use of psychotropic drugs in Norwegian nursing homes. Int I Geriatr Psychiatry 2007, 22:843-9.

8. American Society of Anesthesiologists: New classification of physical status. Anesthesiology 1963, 24:111.

9. Jorm AF: A short form of the Informant Questionnaire on Cognitive Decline in the Elderly (IQCODE): Development and cross-validation. Psychol Med 1994, 24:145-153.

10. Jorm AF: The Informant Questionnaire on cognitive decline in the elderly (IQCODE): A review. Int Psychogeriatr 2004, 16:275-293.

11. Inouye SK, van Dyck CH, Alessi CA, Balkin S, Siegal AP, Horwitz Rl: Clarifying confusion: The confusion assessment method. A new method for detection of delirium. Ann Intern Med 1990, 113:941-948.

12. Bath PA, Morgan K: Differential risk factor profiles for indoor and outdoor falls in older people living at home in Nottingham, UK. Eur J Epidemiol 1999, 15:65-73.

13. Guigoz $Y$, Lauque $S$, Vellas BJ: Identifying the elderly at risk for malnutrition. The Mini Nutritional Assessment. Clin Geriatr Med 2002, 18:737-57.

14. Marcantonio ER, Flacker JM, Wright RJ, Resnick NM: Reducing delirium after hip fracture: a randomized trial. J Am Geriatr Soc 2001, 49:516-22.

15. Milisen K, Foreman MD, Abraham IL, De Geest S, Godderis J, Vandermeulen E, Fischler B, Delooz HH, Spiessens B, Broos PL: A nurse-led interdisciplinary intervention program for delirium in elderly hip-fracture patients. J Am Geriatr Soc 2001, 49:523-32.

16. Lundström M, Olofsson B, Stenvall M, Karlsson S, Nyberg L, Englund U, Borssén B, Svensson O, Gustafson Y: Postoperative delirium in old patients with femoral neck fracture: a randomized intervention study. Aging Clin Exp Res 2007, 19:178-86.

17. Juliebø V, Bjøro K, Krogseth M, Skovlund E, Ranhoff AH, Wyller TB: Risk factors for preoperative and postoperative delirium in elderly patients with hip fracture. J Am Geriatr Soc 2009, 57:1354-61.

18. Gass M, Dawson-Hughes B: Preventing osteoporosis-related fractures: an overview. Am J Med 2006, 119:S3-S11.

19. Parker MJ, Gillespie LD, Gillespie WJ: Hip protectors for preventing hip fractures in the elderly. Cochrane Database Syst Rev 2004, 3:CD001255.

20. Huusko TM, Karppi P, Avikainen V, Kautiainen H, Sulkava R: Randomised, clinically controlled trial of intensive geriatric rehabilitation in patients with hip fracture: sub group analysis of patients with dementia. BMJ 2000, 321:1107-11. 
21. Moseley AM, Sherrington C, Lord SR, Barraclough E, St George RJ, Cameron ID: Mobility training after hip fracture: a randomised controlled trial. Age Ageing 2009, 38(1):74-80.

22. Antonelli Incalzi R, Gemma A, Capparella O: Orthogeriatric unit: a thinking process and a working model. Aging Clin Exp Res 2008, 20:109-12.

23. Pioli $G$, Giusti A, Barone A: Orthogeriatric care for the elderly with hip fractures: where are we? Aging Clin Exp Res 2008, 20:113-22.

\section{Pre-publication history}

The pre-publication history for this paper can be accessed here: http://www.biomedcentral.com/1471-2318/10/65/prepub

doi:10.1186/1471-2318-10-65

Cite this article as: Ranhoff et al:: Older hip fracture patients: three

groups with different needs. BMC Geriatrics 2010 10:65.

Submit your next manuscript to BioMed Central and take full advantage of:

- Convenient online submission

- Thorough peer review

- No space constraints or color figure charges

- Immediate publication on acceptance

- Inclusion in PubMed, CAS, Scopus and Google Scholar

- Research which is freely available for redistribution

Submit your manuscript at www.biomedcentral.com/submit
C Biomed Central 